\title{
EL DERECHO DE AUTOR ANTE LOS DESAFÍOS DEL DESARROLLO EN EL ENTORNO DIGITAL Y LAS COMUNICACIONES EN LOS MOMENTOS ACTUALES
}

\author{
Alcides F. Antúnez Sánchez ${ }^{1}$ \\ Olivia V. Figueredo Paneque ${ }^{2}$ \\ Yolanda Soler Pellicer ${ }^{3}$ \\ Universidad de Granma, Cuba
}

http://dx.doi.org/10.5209/rev_NOMA.2013.v37.n1.42558

\begin{abstract}
Resumen.- El trabajo recoge un eje temático álgido en su conceptualización y ejecución por los entes y agentes que se relacionan con el Derecho de Autor. Hacemos un recorrido por los comienzos de la actividad. El hombre desde su surgimiento ha creado y es lo que siempre lo ha distinguido, sin embargo el autor y el artista durante siglos desconocidos no fueron protegidos ni sus creaciones tampoco hasta el siglo pasado en que se desarrollaron plenamente los conceptos de individualidad, propiedad, derechos naturales o humanos. El derecho de autor puede decirse que existió siempre, pero no era legislado, sino que en las antiguas sociedades, lo creado por los autores se regía por el derecho de propiedad común, es decir, que podía disponer de ellos como una cosa, como cualquier otro bien material. La protección a los autores es relativamente joven aunque desde los períodos más remotos ya existía una noción de propiedad literaria, esto último no podemos negarlo absolutamente, si tenemos en cuenta que en Roma existían verdaderos talleres de copistas que reproducían las obras en manuscritos, ignorando el derecho de autor en el sentido actual. El desarrollo del entorno digital y las comunicaciones en los momentos actuales es vertiginoso. Surgen nuevas formas de expresión y creación, nuevos modos, vías y medios de reproducción y acceso. El proceso de globalización de mercados y economías en que se encuentra inmersa la actual "sociedad de la información" hace cada vez más necesaria la utilización de la informática como instrumento para el tratamiento de datos y su transmisión de un lugar a otro.
\end{abstract}

Palabras clave.- derecho de autor, entorno digital, protección a los autores

\section{El derecho de autor ante los desafíos del desarrollo en el entorno digital y las comunicaciones en los momentos actuales}

Abstract.- The work gathers a thematic algid axis in your |conceptualización| and execution for the beings and agents that it is related with the right side of author. \$3 make a space traveled for the beginnings of the activity we. The man from your |surgimiento| has created and it is which always it has distinguished it, however the author and the artist during unknown centuries were not protected nor your creations neither until the past century in which developed to him fully the concepts of individuality, property, straight natural or human. The right side of author can be said that existed always, but was not legislated, but that in the ancient societies, it created for the authors are governed for the right side of common property,that is to say, that it could dispose of they as a thing, as any other well material. The protection to the authors is relatively young although from the more remote periods already existed a notion of literary property, this the last one cannot refuse it absolutely, if we keep in mind that in blunt existed true workshops of copyists that reproduced the

1 Profesor Derecho Ambiental y Mercantil. Facultad de Ciencias Sociales y Humanísticas. Universidad de Granma. República de Cuba.

${ }^{2}$ Profesora Carrera de Derecho. Facultad de Ciencias Sociales y Humanísticas. Universidad de Granma. República de Cuba.

${ }_{3}^{3}$ Profesora carrera Ciencias Informáticas. Facultad de Ciencias Técnicas. Universidad de Granma. República de Cuba. 
works in manuscripts, by not knowing the right side of author in the current sense. The development of the digital environment and the communications in the current moments is vertiginous. They spring up new forms of expression and creation, new manners, pathes and media of reproduction and access. The process of |globalización| of markets and economies in which finds to him immersed the current thing"society of the information" does more and more necessary the use of the computer science as instrument for the treatment of data and your transmission of a place to other.

Keywords.- right side of author, half-close digitalis, protection to the authors

\section{1.- INTRODUCCION}

Las llamadas culturas primitivas se formaron de manera espontánea y las manifestaciones artísticas o de arte rupestre no pertenecían a nadie en particular sino a todos los miembros del grupo. Con el surgimiento de la escritura como medio de reproducción del conocimiento y como una forma de obtención de ejemplares aparece lo que llamarían "obras" y el sentido de propiedad sobre ellas, pero de una forma muy rudimentaria. Así se van desarrollando las diversas civilizaciones hasta llegar a las modernas y contemporáneas. Con el desarrollo del arte y la ciencia se desarrollan los medios de producción, se inventan las máquinas industriales, filosofía, sociedad y derecho. El hombre desde su surgimiento ha creado y es lo que siempre lo ha distinguido, sin embargo el autor y el artista durante siglos desconocidos no fueron protegidos ni sus creaciones tampoco hasta el siglo pasado en que se desarrollaron plenamente los conceptos de individualidad, propiedad, derechos naturales o humanos.

El derecho de autor puede decirse que existió siempre, pero no era legislado, sino que en las antiguas sociedades, lo creado por los autores se regía por el derecho de propiedad común, es decir, que podía disponer de ellos como una cosa, como cualquier otro bien material. La protección a los autores es relativamente joven aunque desde los períodos más remotos ya existía una noción de propiedad literaria, esto último no podemos negarlo absolutamente, si tenemos en cuenta que en Roma existían verdaderos talleres de copistas que reproducían las obras en manuscritos, ignorando el derecho de autor en el sentido actual.

El papel que desempeña el Derecho de Autor en el mundo de hoy y la diversidad de intereses a los que se aplica, constituye el resultado de una larga y complicada evolución histórica, que expresa la prolongada y vacilante tendencia de la humanidad hacia el establecimiento de normas legales en los asuntos públicos y privados .El reconocimiento del Derecho de Autor como derecho de propiedad se consolidó en la primera mitad del siglo XIX, mediante las leyes generales dictadas en Europa Continental. Sin embargo la protección de tal derecho dentro de los límites del propio Estado no alcanzaba para asegurar su vigencia. 


\section{2.- EL DERECHO DE AUTOR. GENERALIDADES}

En el año 1455 (mediados del siglo XV) Gutenberg perfecciona la imprenta revolucionando con ello la difusión y alcance de las obras escritas y a la vez transforma a estas en objeto de comercio y fin de lucro para os autores. Con la aparición de la imprenta nace la principal manifestación patrimonial del Derecho de Autor: el derecho de reproducción.

La protección apareció primero en forma de "privilegios" de publicación exclusiva concedidos a los editores por diversas autoridades en Inglaterra y en Francia por los Reyes; en Alemania por los Príncipes de los diferentes Estados.

La notable influencia que ejercieron las ideas racionalistas en la Inglaterra del siglo $\mathrm{XVIII}$, provocó un cambio de rumbo en materia de privilegios, comenzaron a concederse definitivamente a los autores. Fue en Inglaterra donde se reconocen las nuevas ideas sobre la propiedad intelectual y en el año 1710 se aprueba la ley conocida como Estatutos de la Reina Ana, la cual revolucionó la concepción que existía hasta entonces, pero era solamente aplicable a libros y nada refería a otros materiales impresos como por ejemplo, las representaciones públicas, las versiones dramáticas, ni las traducciones, por lo que encabezado por el artista satírico inglés Hogarth, surgió con mucho éxito un movimiento a favor de la protección de artistas, dibujantes, y pintores que culminaron con la promulgación de la "Ley de Grabadores de 1735". Hasta 1911 en que se dicta el Copyright Act el Derecho de Autor en Inglaterra se rigió por el Common Law para las obras no publicadas y los derechos personales, luego de publicadas por el Estatuto.

El ejemplo inglés fue seguido por Alemania y Francia, y esta última como consecuencia de las ideas imperantes en esa época en la revolución Francesa abolió todo tipo de privilegio y en 1791 y 93 la Asamblea Constituyente sentó las bases del sistema de Derecho de Autor francés con la promulgación de dos decretos: "La ley relativa a los espectáculos" de 1791 y la "Ley relativa a los derechos de propiedad de los autores de todos géneros, de los compositores de música, los pintores y diseñadores" de 1793, que estuvieron en vigor hasta 1957, por el largo tiempo que estuvieron vigentes demuestran que estos decretos contenían elementos básicos muy avanzados para su época y la jurisprudencia jugó un papel en su perfeccionamiento.

En Alemania si bien existieron los privilegios se estableció una práctica de la firma previa entre autores y editores de contratos que incluso prevalecían sobre aquellos. Luego el pensamiento filosófico de Kant influenció grandemente los Derechos de Autor, quien vio a los derechos de autor no solo como una propiedad sino como extensión o reflejo de la personalidad del autor, por lo que esta debía protegerse también. Esta corriente influenció en toda Europa llevando al desarrollo del Derecho Moral de autor. En 1837 Prusia promulgó la primera ley alemana moderna reconocida en toda Alemania. 
En EUA la legislación de Derecho de autor se hace efectiva entre 1783 y 1786, estando muy ligada a los Estatutos de la reina Ana, hasta que en 1976 se dicta otra Copyright Act.

La legislación francesa sirvió de base para la posterior evolución de la doctrina y la legislación burguesa en la que se inspiró el Código Civil Español de 1889 y sus normas complementarias contenidas en la Ley de Propiedad Intelectual de 1879 y su reglamento.

Para ubicar al derecho de autor dentro de los derechos de propiedad intelectual es necesario aclarar que coexisten dos sistemas jurídicos: el de origen Anglosajón o de Common Law, que tiene como centro el derecho de copia y en el que el derecho de autor se denomina copyright, y el de origen latino o de tradición continental europea basado en el derecho romano o romano germánico, nacido de los derechos franceses, más cercanos a sus orígenes, a los derechos personales.

Por todo ello podemos concluir que el Copyright Angloamericano y el Droit d'auteur francés, constituyeron el origen de la moderna legislación sobre derecho de autor en los países de tradición jurídica basada en el Common Law y de tradición jurídica continental europea o latina y el reconocimiento del Derecho de Autor como derecho de propiedad se consolidó en la primera mitad del siglo XIX, mediante las leyes generales dictadas en Europa Continental.

\section{3.- CONCEPTO. OBJETO. CRITERIOS DE PROTECCIÓN. CONTENIDO DEL DERECHO DE AUTOR}

Los criterios más generalizados en relación con el concepto del Derecho de Autor son aquellos que los postulan como el derecho que protege el trabajo del creador y por ende los derechos subjetivos de su actividad intelectual; por ello podemos definir el Derecho de Autor como: El conjunto de normas jurídicas, principios, valores que van a regular y proteger los derechos exclusivos de los autores, sobre el producto de su creación que se integra por toda una serie de facultades y prerrogativas de carácter personal y otra serie de facultades de carácter patrimonial o pecuniario.

\section{El objeto de protección del derecho de autor es la obra}

Para el Derecho de autor, obra es la expresión personal de la inteligencia que desarrolla un pensamiento que se manifiesta bajo una forma perceptible, tiene originalidad o individualidad suficiente, y es apta para ser difundida y reproducida.

En el lenguaje común, el término obra es "cualquiera producción del entendimiento en ciencias, letras o artes"; para el Glosario de la OMPI sobre derecho de autor y conexos es, "toda creación intelectual original expresada en una forma reproducible". 
Ahora bien, el CB, como la mayoría de las legislaciones nacionales, incluida la nuestra, no define el vocablo "obra", pues se limita a señalar que se encuentran protegidos los derechos de los autores sobre sus obras literarias y artísticas a cuyos efectos hace una enumeración ejemplificativa de las creaciones objeto de tutela

\section{Criterios de protección}

1. Protección a la forma no a las ideas: Las ideas en si mismas consideradas, por más novedosas y brillantes que sean, no son objeto de protección, tienen que concretarse en un soporte material. Se protege la exteriorización de su desarrollo en obras aptas para ser reproducidas, representadas, etc

2. Originalidad: en materia de Derecho de autor la originalidad reside en la expresión o forma representativa creativa e individualizada de la obra. Para éste Derecho esto no es lo mismo que novedad. Originalidad significa que la obra sea producto de una particular expresión del autor, donde se ponga de manifiesto su impronta personal. Una obra es original en la medida en que no sea copia de otra. Una obra es original a pesar de que parta de una idea que no lo sea. Muchos han escrito novelas de amor, pero cada una de ellas es original e independiente, pues cada autor tuvo su estilo para escribirla y eso s lo que protege el derecho de autor. La originalidad no puede apreciarse de la misma manera en todos los tipos de obras.

3. Formalidades: Es universalmente aceptado que la protección que otorga el derecho de autor sobre una obra comienza desde el mismo momento de la creación, sin que se requiera ningún tipo de registro o formalidad. Por lo tanto no nace de la autoridad administrativa.

\section{Criterios ajenos al reconocimiento del Derecho}

Calidad, Mérito, Destino y forma de expresión: La protección concedida por el derecho de autor es totalmente independiente del valor o mérito de la obra, se trata de una cuestión de gustos y si es buena o no le corresponde al público y la crítica decirlo, no es una cosa que interese al derecho. Grandes obras como la Traviata de Verdi y la Consagración de la Primavera de Stravinsky fueron abucheadas, tampoco interesa el destino, que sea cultural, científico, política, lo que interesa es que sea una obra literaria o artística. Tampoco interesa su forma de expresión, puede ser oral o escrita, representada o fijada, etc.

\section{Contenido del Derecho de Autor}

La obra protegida por el derecho de autor tiene sus propias características particulares, refleja la personalidad de su creador. Como dijera Delia Lipszyc el autor vive y trasciende en su obra, por eso el derecho de autor no sólo protege los posibles beneficios que el autor pueda obtener sino las relaciones intelectuales y personales con la obra y su utilización. 
La especialidad del derecho de autor nos obliga a distinguir dos aspectos fundamentales de su contenido. La obra creada por su naturaleza va a reflejar la personalidad del autor y va a perdurar en el tiempo y su autor va a tener la posibilidad de aprovechar económicamente su obra, es decir, que va a crear un vínculo personal y económico con su obra. Es por ello que se reconocen dos aspectos en el derecho de autor:

El elemento personal o moral que se fundamenta en el respeto a la personalidad del autor y la defensa de su obra.

El elemento patrimonial que posibilita que el autor viva de su obra, es decir, efectúe su explotación económica o la autorice.

El derecho moral consiste en un determinado número de prerrogativas que proceden de la necesidad de preservar a la vez la integridad de las obras intelectuales y la personalidad de los mismos.

\section{Características del Derecho moral}

- Esenciales: porque contienen un número de derechos exigibles sin los cuales la condición de autor perdería su sentido;

- Extrapatrimoniales: no son estimables en dinero aunque producen consecuencias patrimoniales

- Inherentes: porque están unidos al artista

- Absolutos: porque es oponible a cualquier persona (erga omnes)

- Inalienables: lo cual lo hace inembargable, inejecutable e inexpropiable

- Irrenunciables (vincularlo con inherente)

- Imprescriptible: está fuera del comercio, y por ser personales, inherentes al autor, lo cual es o mismo que decir perpetuos.

- Insubrogable: por ser inherente al artista.

Las facultades que componen los derechos morales tienen un contenido diferente, dividiéndose en dos categorías:

Positivas: En las que el autor es el que actúa y toma decisiones y;

Negativas: También llamadas defensivas, porque en ellas el autor impide que se realice algo o se abstiene de realizar alguna acción, además de que aún después de la muerte del autor y antes de que la obra entre en dominio público puede reclamar sus derechos.

Los derechos morales básicos son:

$\checkmark \quad$ Derecho de Divulgación (positiva): el autor es la única persona facultada para decidir, a su libre voluntad, si la obra puede ser comunicada o no al público y fijar las modalidades de su divulgación. 
$\checkmark \quad$ Derecho de paternidad (negativa): Es el derecho del autor a que se reconozca su condición de creador de la obra, de decidir si la obra se publica bajo su nombre o en forma anónima o seudónima; este derecho comprende: a) el derecho de reivindicar su condición de autor o la forma en que menciona el mismo y b) el derecho de defender su autoría cuando ella es impugnada.

$\checkmark \quad$ Derecho al respeto a la integridad de la obra (negativa): el derecho del autor de hacer respetar el contenido y calidad de la obra e impedir cualquier cambio, deformación, etc., sin autorización del autor.

$\checkmark \quad$ Derecho de arrepentimiento (positiva): También llamado al retiro o retracto, es el derecho del autor a decidir la no divulgación de la obra y a retirarla del comercio una vez divulgada. Esta se trata de una facultad excepcional, opuesta a la fuerza obligatoria de los contratos. Este derecho está reservado al autor y no se transmite a sus herederos.

\section{Los Derechos patrimoniales}

Quien tenga éxito en le público, con su actividad intelectual, también obtiene por ella ingresos e incluso puede vivir de ella eventualmente. Los derechos de autor que deben asegurar al autor un ingreso por su trabajo se denominan "Derechos Patrimoniales.

Características de los derechos patrimoniales:

$\checkmark$ Es un derecho exclusivo: Esto implica que sólo el autor o titular, sus herederos o causahabientes pueden autorizar la utilización o explotación económica de una obra determinada, por cualquier medio o procedimiento.

$\checkmark$ Es un derecho transferible: Puede ser cedido o transmitido a terceras personas ya seas gratuita u onerosa, total o parcial.

$\checkmark$ Es un derecho renunciable: A diferencia del Derecho moral, se pueden renunciar a estos derechos lo que implicaría que cualquiera utilizaría la obra sin necesidad de pagar ninguna retribución económica, pero respetando los de carácter moral.

$\checkmark$ Es un derecho de duración limitada: Se extingue de acuerdo con los Convenios y a las leyes nacionales en un determinado número de años después de la muerte del autor o de la publicación de la obra.

El contenido de los derechos patrimoniales establece las diferentes formas y medios mediante los cuales una obra puede ser explotada o aprovechada económicamente. Existen tres divisiones básicas en el derecho patrimonial que van a comprender casi todas las modalidades de uso de las obras y son:

\footnotetext{
$\checkmark$ Derecho de Reproducción

$\checkmark$ Derecho de Comunicación Pública

$\checkmark$ Derecho de Transformación.
} 


\section{El Derecho de Reproducción}

Se define por los tratadistas como la facultad de explotar la obra mediante su fijación material en cualquier medio y mediante cualquier procedimiento, lo cual permite obtener copias o ejemplares de la obra para su difusión al público.

La reproducción comprende:

- La edición

- La reproducción sonora o audiovisual

- Reproducción gráfica

- Reproducción de obras en sistema de computador

- Realización de uno o más ejemplares de una obra tridimensional en bidimensional.

\section{El Derecho de Comunicación Pública}

Es la facultad de explotar la obra mediante el acto de hacerla accesible al público, ya sea de manera directa (representación en vivo), o indirecta (discos, cintas), o mediante cualquier forma de radiodifusión o distribución por cable.

Este derecho comprende de forma general lo siguiente:

- Representaciones escénicas

- Comunicación por palabra hablada

- Ejecución pública de obras musicales

- Radiodifusión y cable

- Cinematografía

\section{El Derecho de Transformación}

Consiste en la facultad o poder jurídico exclusivo que se le confiere al autor de autorizar a otro la creación de obras derivadas a la suya. Existen obras que pueden no ser originales plenamente, pero pueden tener valor creativo para el derecho, como son las traducciones; adaptaciones; extractos; parodias; etc.

Es decir, las obras producto de intelecto humano pueden transformarse al igual que cualquier otra, de tal manera que puede dar lugar a otra obra protegida por el derecho de autor como obra derivada.

El contenido del Derecho de transformación está muy vinculado con el derecho moral de integridad de la obra, pero no debe confundirse, ya que el de integridad se refiere a que el autor puede oponerse a toda deformación de la obra que se haga sin su consentimiento. Está vinculado porque aún y con la autorización del autor, si la transformación perjudica la reputación de la obra o del autor, este puede en virtud del derecho moral oponerse y reclamar por esa infracción. 
Existen otros tipos de derechos patrimoniales que han sido reconocidos, como son.

- El derecho de distribución: el cual incluye la venta, alquiler, préstamo u otra forma de utilización económica para ponerla a disposición del público. En este caso el autor determinará, si esto ocurre o no, bajo qué condiciones y en qué territorio. En los casos de este derecho debe reconocerse el agotamiento del derecho o la primera venta (first sale).

- Derecho de participación o Droit D' Suite: es el derecho de los autores de obras artísticas a percibir una parte del precio de las ventas sucesivas posteriores a la primera enajenación de los originales de dichas obras realizadas en subastas públicas o con intervención de agentes comerciales).

El derecho de Autor ha probado que es idóneo para estimular la actividad creativa al asegurar al creador la posibilidad de obtener una retribución económica, el respeto por su obra y el reconocimiento de su condición de autor; además beneficia al empresario al garantizar su inversión, permitiendo el auge de las industrias culturales con el consiguiente provecho para la comunidad al fomentar la difusión de obras.

\section{El Derecho de Autor a la luz del desarrollo de las nuevas tecnologías}

Un aspecto que ha generado muchos debates es la posibilidad del derecho de autor de proteger y estimular la creación ante las transformaciones que se están produciendo con la aplicación de las nuevas tecnologías. El momento actual es, sin dudas, un momento de cambios tecnológicos que han marcado decisivamente la evolución y los contenidos del derecho de autor, desde su mismo nacimiento como sistema para la protección jurídica de ciertas creaciones del espíritu humano.

Así ha ocurrido, como es sabido, con la radio, fonografía, imprenta y la televisión de modo que los Tratados Internacionales y las leyes nacionales en materia de derecho de autor lo afirman. Por tanto, la informática y las creaciones intelectuales relacionadas con esta, no han sido la excepción.

El desarrollo del entorno digital y las comunicaciones en los momentos actuales es vertiginoso. Surgen nuevas formas de expresión y creación, nuevos modos, vías y medios de reproducción y acceso. El proceso de globalización de mercados y economías en que se encuentra inmersa la actual "sociedad de la información" hace cada vez más necesaria la utilización de la informática como instrumento para el tratamiento de datos y su transmisión de un lugar a otro. Tal es su grado de incidencia social que ya nadie puede desconocer que la informática está experimentando en la actualidad una creciente "masificación".

El fenómeno de uso masivo de la informática afecta, en primer lugar, a los sistemas informáticos u ordenadores, que ha dejado de ser un bien escaso, para 
convertirse, prácticamente, en un producto de masas. Esto ha provocado en el mercado un incremento espectacular de la demanda de programas informáticos. El programa de ordenadores es un conjunto de instrucciones expresadas mediante palabras, códigos, planes o en cualquier otra forma, que al ser incorporadas en un dispositivo de lecturas automatizadas y traducidas en impulsos electrónicos, pueden hacer que un ordenador ejecute determinada tarea u obtenga determinado resultado.

El problema planteado al derecho de autor en este sentido, ha consistido en la necesidad de tutelar adecuadamente los esfuerzos creativos y empresariales exigidos para la realización, producción y distribución de determinadas informaciones y contenidos especialmente valiosos, desde un punto de vista económico y social frente a los riesgos de una apropiación indebida de dicha información y contenidos por terceros. Sin embargo, la protección jurídica de las creaciones intelectuales relacionadas con la informática presenta dos rasgos peculiares: de un lado la globalización de la economía la cual ha propiciado o está propiciando desde el comienzo una respuesta internacional que asegure una regulación básicamente uniforme a escala mundial, acusada en los ámbitos regionales de integración de mercados nacionales; de otro lado, la calidad tecnológica y el avance de las normas existentes así como su interpretación, están permitiendo que el acomodo o ajuste de las nuevas reglas en el sistema de protección jurídica de la propiedad intelectual no sea excesivamente traumático.

Es cierto que algunas de estas novedades introducidas han afianzado un deslizamiento desde un modelo de derecho de autor basado en los postulados humanistas y de la política cultural, a otro más atento a las exigencias de la inversión empresarial.

En particular, las creaciones informáticas que han merecido la atención del moderno derecho de autor son los programas de ordenador y las bases de datos. Los primeros son la estructura principal de Internet y el uso de ellos es indispensable para ejecutar, reproducir y registrar una gran cantidad de otras obras protegidas, tales como: videos, obras musicales, multimedia etc.

Los programas de computación no siempre han estado bajo la égida del Derecho de Autor, al principio aparecieron unidos a las máquinas, y es por esta razón que se les entendía en el marco de protección de la Propiedad Industrial. Años más tarde, estas creaciones se separan definitivamente de su soporte primitivo, para conformar un mercado diferente y por tanto con nuevos intereses, de ahí que se comenzara a analizar si estos se debían mantener como objeto de la Propiedad Industrial, si debían ser objetos de protección de una legislación específica o si eran parte del Derecho de Autor. Finalmente, después de muchas discusiones y debates, la práctica demostró que estos eran obras del intelecto humano, de ahí que se decidiera que comenzaran a formar parte de la ya extensa lista de obras que el Derecho de Autor ampara, siempre y cuando cumplan con el requisito de originalidad. 
Los programas de computación se expresan a través de un lenguaje escrito, aunque una buena parte del mismo sólo pueda entenderlo la máquina, de ahí que para los fines del Derecho de Autor se les homologa a las obras literarias.

Las obras literarias desde el punto de vista de derecho de autor se entienden como todas las obras escritas originales, sean de carácter literario, científico, técnico o meramente práctico, prescindiendo de su valor y finalidad; en un sitio de internet podemos encontrar múltiple información escrita, memorias descriptivas.., la introducción de un obra en una página web, accesible a través de internet constituye un acto de comunicación pública y precisa la autorización expresa del autor para visualizar y descargar la obra. Los segundos, son compilaciones sistemáticas de cualquier elemento, sean protegidos o no por el derecho de autor, donde la originalidad radica en el método de selección. Con los términos "bancos de datos" y 'bases de datos" se describen los depósitos electrónicos de datos y de información un sistema de manejo y de control.

En el ámbito internacional, los programas de computación son regulados por vez primera en el Acuerdo sobre los Aspectos de Propiedad Intelectual relacionados con el Comercio, ADPIC, en el que los países desarrollados mostraron su preocupación por proteger sus industrias y con ellas, salvaguardar sus derechos intelectuales, los que estaban siendo utilizados indiscriminadamente, sin la autorización de sus titulares, provocando un perjuicio económico considerable. El artículo 10 de este Acuerdo, obliga a los Estados Miembros de la OMC a proteger a los programas de computación, sean programas fuente o programas objeto, en virtud de la misma protección que el Convenio de Berna le otorga a las obras literarias.

A partir de la adopción del acuerdo ADPIC, los países tuvieron la necesidad de ir adecuando sus legislaciones internas a los límites convencionales establecidos por este Acuerdo; y como parte de este proceso han ido incluyendo en las legislaciones de Derecho de Autor a los programas de computación como parte del catálogo de obras protegidas por el Derecho de Autor.

Otro de los tipos de obras que han ido surgiendo gracias al desarrollo tecnológico son las bases de datos, que constituyen compilaciones de datos, hechos, etcétera. Para conformar este tipo de creación, siempre hay que disponer de un contenido que, lo constituyen los hechos o datos que se insertan, si estos no constituyen una obra per se, entonces la base de datos es original, pero si el contenido que se utiliza constituye una obra preexistente, con determinado nivel de titularidad, entonces la base de datos se considera una obra derivada, ya que para su creación se ha tomado como base una obra preexistente.

Existen algunos requisitos que deben cumplir aquellos que se disponen a crear una base de datos cuando éstas contienen obras originarias preexistentes, entre ellos el pedir autorización al autor o titular de la obra a utilizar, si esta se encontrare en dominio privado; respetar el nombre del autor, elemento este a tener en cuenta tanto en el caso anterior, como en aquellas obras que se 
encuentren en dominio público. Suele pensarse que las bases de datos solo se refieren a aquellas compilaciones que se hacen en un formato electrónico, pero la realidad es que se consideran como tales tanto aquellas que están en formato electrónico como las que están en papel, y así lo establece el artículo 10.2 de los ADPIC.

En nuestro país, gracias al carácter enunciativo del objeto de protección, regulado en el artículo 7 de la Ley 14 de 1977, Ley de Derecho de Autor, los autores de programas de computación y las bases de datos han encontrado los principios generales de tutela de sus derechos. No obstante, debido a la necesidad de contar con disposiciones específicas para estos tipos de obras, fue dictada la Resolución Conjunta No. 1, de 21 de junio de 1999 entre el MINCULT y el SIME, la cual establece el reglamento para la protección de los programas de computación y bases de datos, en cuanto a su creación, concertación de contratos, así como su explotación comercial. Esta normativa contiene las regulaciones más específicas en la materia, extiende la protección no sólo a los programas originales, sino también a las versiones sucesivas y programas derivados; establece las reglas de autoría y titularidad para a los autores de estos tipos de obras que realicen sus creaciones de forma independiente, por encargo, o en el marco de un empleo.

La Resolución Conjunta No. 1/99, ha devenido como paliativo en el proceso de transición de nuestras disposiciones autorales hacia una nueva legislación adecuada a los cambios que en el mundo se han venido dando en esta materia y a los convenios internacionales de los cuales nuestro país es signatario.

Por otro lado la oferta por la red de software es enorme, desde programas antivirus y sus actualizaciones hasta programas operativos.

Un problema al que ya comienzan a enfrentarse los desarrolladores y usuarios de software libre, así como aquellos que utilizan licencias para la distribución de sus creaciones y contenidos, y que habrá que solucionar, es el de la "exportodependencia". Ya han aparecido los primeros casos de violación de las licencias libres y se carece de medios para defenderlas, el software libre, en esencia, encierra tres libertades:

$>\quad$ Copiar el programa y darlo a tus amigos o compañeros de trabajo

$>\quad$ Cambiar el programa como desees ya que se tiene acceso al código de fuente y;

$>\quad$ Distribuir una versión mejorada ayudando así a contribuir la comunidad.

En el mundo del software libre se utiliza el marco legal de los derechos de autor para colectivizar los derechos que el autor tiene sobre el software, incluyendo los derechos de copia, uso y modificación. Lo único que no está permitido hacer es que se apropien de ella. Precisamente nuestro código penal sin hacer un análisis profundo no regula de forma expresa y tácita en un título destinado para ello los delitos informáticos. 
El precio de algunos programas en el mercado, provoca en ocasiones un doble efecto:

1. La obtención de importantes ingresos económicos por parte de los empresarios dedicados a la elaboración de ordenadores y de programas, por la venta de sus productos y,

2. la proliferación de copias ilegales exactamente idénticas a la obra original y su comercialización en el mercado clandestino por un precio sensiblemente inferior al del original copiado, ocasionando importantes pérdidas económicas a las empresas informáticas. Este efecto es un fenómeno más amplio que algunos lo identifican como "la cultura del pirateo" (libros, fonogramas, películas de videos o señales televisivas) correspondientes a emisoras de pago, son junto a los ya referidos programas de ordenador, algunos de los objetos de pirateo más habituales. Por lo que respecta a los programas informáticos, según datos de la Business Software Alliance y la Software Publishers Association, de los 523 millones de programas informáticos utilizados en 1996 en todo el mundo, 225 millones, esto es casi la mitad, eran piratas. Ello representó entonces una pérdida de 11,2 billones de dólares.

No es difícil inferir que las implicaciones de un entorno global digitalizado donde las personas actúan desde el anonimato son altamente conflictivas con un sistema de regulación de conductas y atribución de responsabilidades por los actos que se realizan, como lo es el derecho, lo cual hace muy dificultoso establecer regulaciones eficaces en el ciberespacio.

Aún más, algunos autores estiman que la relevancia de la ley como medio de protección de los derechos del autor, se encuentra en franca disminución en la era digital, pues sostienen que: los modelos empresariales y las herramientas tecnológicas evolucionarán en el tiempo para hacer de la ley de derechos de autor una herramienta cada vez menos importante para modelar la conducta de los usuarios en Internet.

En mi opinión aún y cuando el tiempo implique o genere desarrollo, fundamentalmente para las nuevas tecnologías, el derecho de autor juega un papel preponderante y de excelencia para la protección de la creación de las obras pues, las regulaciones jurídicas antes mencionadas protegen los derechos de los autores creadores de este tipo de obras.

Para muchos el propósito de estos avances consisten en impedir la reproducción ilegal de productos intelectuales creados con un fin, un objetivo y un destino como los sistemas de codificación y la creación de discos compactos no reproducibles y se ciñen en las vías tecnológicas, absolutizando incluso, la protección de su creación a este medio, degradando la protección jurídica que le aporta el derecho de autor; donde se destacan:

- $\quad$ La fabricación de discos compactos que no pueden ser reproducidos en los computadores, lo cual haría inútil el empleo de aparatos como quemadores de 
discos compactos, así como la elaboración de copas en las computadoras y, con ello, su distribución a través de internet.

- $\quad$ La inclusión de limitaciones en la obra.

- Existe también una antigua técnica de ocultación datos que se llama “estegnografía"la cual viene del griego stegos, que significa cubierta, por lo que estecnografía significaría "escritura oculta', la cual está muy relacionada a la criptografía, es por tanto el conjunto de técnicas que nos permiten ocultar o camuflar cualquier tipo de datos.

Sin embargo para muchos hoy en día aún resulta poco claro la posibilidad real de ejercer un control sobre el uso de las obras protegidas por el derecho de autor en internet y en especial la protección de los programas de ordenador; ya que el uso de las obras protegidas por este derecho no cuenta con una regulación específica cuando el acceso a las mismas se realiza en el entorno global de la red.

Ahora, bien, es una realidad que en la red se pueden imponer ciertas restricciones, como lo son las claves de acceso, las Watermarks o la fabricación de discos compactos que no pueden ser reproducidos en los computadores, pero es una realidad también, que estas pueden violarse de manera fácil, así que, aunque se tenga una gran cantidad de protección, hay que tener en cuenta la posibilidad de que esta no sea suficiente, y se haga más necesario el peso de la ley en este sentido.

Por otra parte, el internet es un complejo de sistemas de intercomunicación de computadoras y redes de computadores con alcance mundial, que ofrece indeterminados servicios como: el correo electrónico, o e-mail y otros, por cuanto estos, son medios que permiten una intercomunicación y disponibilidad de las creaciones del intelecto humano nunca antes visto, esta red de redes forma parte una comunidad real, Ilamada también Ciberespacio, conformada por personas que pueden interactuar entre ellas a voluntad, internet se encuentra realmente abierta a cualquier persona que quiera ingresar sin importar orígenes, nacionalidad, limitaciones físicas y geográficas etc.

Pero la facilidad con que se infringen las leyes y la dificultad para detectarlo y hacerlas cumplir, obliga a quienes tengan un interés legítimo en proteger el derecho de explotación exclusivo del titular del derecho de autor de una obra, a tener que recurrir más a la tecnología que a las leyes en sí mismas, como serían los dispositivos de autopreparación.

Es evidente que los informáticos y las personas que son capaces de crear estos programas o desarrolladores de sistemas informáticos y sus software, no tienen la claridad absoluta de la necesidad de proteger sus derechos y del papel que desempeña el derecho de autor en este sentido o sencillamente llevan en detrimento esta institución. No cabe dudas que el derecho de autor merita un despertar y fundamentalmente en los países en desarrollo, sin hacer un análisis profundo del asunto, pues las regulaciones de estas deben enfocarse más en los adelantos que propicia la ciencia y la técnica. 


\section{¿Dónde usted puede registrar su obra?}

\section{Registro Nacional del Derecho de Autor}

Radica en la sede del CENDA, con un horario de 9.00 a.m. a 12 se realiza el registro y depósito de obras, actos y contratos.

Los tipos de obras que se pueden registrar integran el vasto catálogo de las manifestaciones artísticas y literarias, entre ellas: pinturas, fotografías, novelas, cuentos, poesía, obras de teatro, coreografías, guiones cinematográficos, libretos de radio y televisión, obras musicales, programas de computación y bases de datos, entre otros.

Resulta ser una prueba a primera vista ante tribunales, así como una garantía jurídica de la condición de su autoría y titularidad, por tanto, le es útil no solo a los creadores, sino también a las empresas y entidades que encargan.

\section{4.- CONCLUSIONES}

El fenómeno del uso masivo de la informática afecta, en primer lugar, a los sistemas informáticos $\mathrm{u}$ ordenadores, que ha dejado de ser un bien escaso, para convertirse, prácticamente, en un producto de masas, esto ha provocado un incremento espectacular en las demandas de los programas informáticos que necesitan de la tutela adecuada del derecho de autor para la protección de los derechos del autor de una obra, para la realización, producción y distribución de determinadas informaciones y contenidos especialmente valiosos, desde un punto de vista económico y social frente a los riesgos de una apropiación indebida de dicha información y contenidos por terceros.

La protección jurídica de las creaciones intelectuales relacionadas con la informática presenta dos rasgos peculiares: de un lado la globalización de la economía la cual ha propiciado o está propiciando desde el comienzo una respuesta internacional que asegure una regulación básicamente uniforme a escala mundial, permitiendo que se ajuste a las nuevas reglas en el sistema de protección jurídica de la propiedad intelectual y que, no sea excesivamente traumático. Para ello se encuentran regulada la protección de los programas de computación siempre y cuando cumplan con el requisito de originalidad como obras literarias, a nivel nacional e internacional así como las Bases de Datos

Además de la Ley 14 de 1977 y los tratados internacionales que protegen los derechos de los autores de programas de computación y bases de datos, existen disposiciones específicas para estos tipos de obras, fue dictada la Resolución Conjunta No. 1, de 21 de junio de 1999 entre el MINCULT y el SIME, la cual establece el reglamento para la protección de los programas de computación y 
bases de datos, en cuanto a su creación, concertación de contratos, así como su explotación comercial.

Los criterios de los involucrados en las creaciones de este fenómeno del entorno digital, las nuevas tecnologías y la comunicaciones tienen como tendencia en los momentos actuales favorecer más a la tecnología a través de los dispositivos de autopreparación que a las leyes, producto a la facilidad con que se infringen las leyes y la dificultad para detectarlo y hacerlas cumplir, obliga a quienes tengan un interés legítimo en proteger el derecho de explotación exclusivo del titular del derecho de autor de una obra, a tener que recurrir más a la tecnología que a las leyes en sí mismas.

En el mundo del software libre se utiliza el marco legal de los derechos de autor para colectivizar los derechos que el autor tiene sobre el software, incluyendo los derechos de copia, uso y modificación. Lo único que no está permitido hacer es que se apropien de ella.

\section{5.- BIBLIOGRAFÍA}

1. ÁlVAREZ TABíO, Dr. Fernando. Comentarios a la Constitución Socialista, Editorial Pueblo y Educación, 1988. La Habana. Cuba.

2. BARRERA GRAF, Jorge. El Derecho Mercantil en la América Latina. Editora Universidad Nacional Autónoma de México. 1963.

3. BROSETA PONT, Manuel. Manual de Derecho Mercantil, Editorial Tecnos S.A, Madrid, España, 1991.

4. BEAUMONT CALLIRGOS, Ricardo. Tratado de Derecho Mercantil. Tomos I y II. Instituto Peruano de Derecho Mercantil. Ley general de sociedades. Títulos valores. 2004.

5. BAUZÁ REILLY, Marcelo: Nombres de Dominio y Derecho. Problemática y Líneas Evolutivas. Revista de Derecho e Informática. Disponible en http://www/funredes.org/mistica/castellano/emec/producción/memorias6/0906.html.

6. BENVENUTO VERA. Ángelo: El Delito Informático, Ley 19.223. Disponible en http://www.hes-cr.com/secciones/dere-info.htm.

7. COLECTIVO DE AUTORES, Selección de Lecturas de Derecho de Autor. Ed. Félix Varela, La Habana, 2001.

8. CEPEDA C., Verónica: Hacia la Seguridad-Imperio de la Ley. Diario La Hora, Quito, Ecuador.

9. CABANELLAS, Guillermo, Tratado de Derecho Laboral, Buenos Aires, Editorial Heliatra S.R.L., tercera edición, 1989, Tomo II, volumen 3, página 362. Argentina.

10. COLECTIVO DE AUTORES, Nociones de Derecho Mercantil, Editorial Félix Valera, Ministerio de Educación Superior. La Habana. Cuba. 2004, pág.17.

11. COLECTIVO DE AUTORES. El Perfeccionamiento empresarial en Cuba. Editorial Félix Varela. La Habana. 1999.

12. COLECTIVO DE AUTORES. La empresa y el empresario en Cuba. Editora ONBC. La Habana. Cuba. 2000. 
13. COLECTIVO DE AUTORES: Nociones de Derecho Mercantil (para estudiantes de contabilidad), $1^{a}$ ed., Editora Félix Varela, Ministerio de Educación Superior. La Habana, 2004.

14. COLECTIVO DE AUTORES. La nueva Universidad Cubana y su contribución a la universalización del conocimiento. Editora Félix Varela. La Habana. Cuba. 2006. Págs. 361-389.

15. COLECTIVO DE AUTORES, Temas de Derecho administrativo cubano. Editorial Félix Varela. La Habana. Cuba. 2005.

16. COLECTIVO DE AUTORES. Estudios de Derecho Administrativo. Editora Félix Varela La Habana. Cuba 2005.

17. COLECTIVOS DE AUTORES. Derecho Constitucional Cubano. Editorial Félix Varela La Habana 2005.

18. CAÑIZARES ABELEDO, Dr. Fernando. Teoría del Estado y el Derecho Tomo I, II. Editora Pueblo y Educación. La Habana 1979. Cuba.

19. CRUZ, Marta y Emilia Horta Herrera: Selección de lecturas de Propiedad Industrial (2 tomos), Editorial Félix Varela, La Habana, Cuba, 2003.

20. FIRMA ELECTRONICA. Ley 59 de 2003, de 19 de diciembre. Disponible en http://www.cddhcu.gob.mx/camdip/foro/df/ser_tel.htm.

21. UNED. Revista Iberoamericana de Derecho Informático. XIV Tomos. España. 1.996.

22. URÍA, Rodrigo: Curso de Derecho Mercantil, Editorial Marcial Pons, Madrid. España. 2003.

23. LIPSZYC, Delia, Derecho de Autor y derechos conexos, Tomos I y II, Ed. Félix Varela, La Habana, 2000.

24. LÍBANO MANZUR, Claudio: Los Delitos de Hacking en sus diversas manifestaciones. Disponible en http://www.comunidad.derecho.org/ peru. html.

25. Ley Especial Contra los DELITOS INFORMÁTICOS, Venezuela, artículo

2.I).

26. LINEAMIENTOS DEL PARTIDO COMUNISTA DE CUBA. 6to congreso. Año 2011.

27. GONZÁLEZ Gómez, Diego: Marco Legal en Europa y España Sobre delitos Informáticos. Revista de Derecho e Informática. Disponible en http://www/funredes.org/mistica/castellano/emec/producción/memorias6/0906.html. 28. GARCÍA NOGUERA, Noelia- DELITOS INFORMÁTICOS EN EL CÓDIGO PENAL ESPAÑOL. Pág. 5

29. Ley No. 19.223 De los DELITOS INFORMÁTICOS, Chile, prólogo.

30. GIRALDO, Jaime. INFORMÁTICA JURÍDICA DOCUMENTAL. Temis. Colombia. 1990. Pág. 192.

31. RODRIGO URÍA Y MENÉNDEZ AURELIO (Coordinadores). Curso de Derecho Mercantil, Tomo I, Editorial Civitas S.L, Reimpresión, Madrid, España, 2001.

32. RUIZ DE VELASCO, Adolfo. Manual de Derecho Mercantil, Editores Deusto S.A., Bilbao, España, 1992

33. MAGLIO, Marco. LA TUTELA DEI DATI PERSONALI. Napoli, Edizioni Giuridiche Simone. 1999.

34. MAZEAUD, Jean. LECCIONES DE DERECHO CIVIL. Parte Primera. Volumen I. Ediciones Jurídicas Europa-América. Buenos Aires. 1959. 
35. SAGUES, Néstor. HABEAS DATA: SU DESARROLLO CONSTITUCIONAL, en AAVV, Lecturas Andinas Constitucionales $\mathrm{N}^{\circ} 3$, Comisión Andina de Juristas, Perú. 1994.

36. SALAZAR, Edgar. CIBERNÉTICA Y DERECHO PROCESAL CIVIL. Ediciones Técnico-Jurídicas. Caracas. 1979. Pág. 264.

37. TÉLLEZ, Julio. DERECHO INFORMÁTICO. 2a. Edición. México. 1996. Pág. 283.

38. GONZÁLEZ GÓMEZ, Diego: Marco Legal en Europa y España Sobre delitos Informáticos. Revista de Derecho e Informática. Disponible en http://www/funredes.org/mistica/castellano/emec/producción/memorias6/0906.html. 39. VILA NOYA, MSc. Lisette: El trabajo por cuenta propia en Cuba. Trabajo de ejercicio académico que le sirvió para homologar en Cuba el título de Máster en Derecho Mercantil y Financiero de la Universidad de Barcelona. España. Editora ONBC. 1999. La Habana. Cuba.

40. VIVANTE, César. Derecho Mercantil. Tribunal Superior de Justicia Federal. Universidad de Bolonia. Italia. Editora Madrid. España. 2003.

41. VIAMONTES GUILBEAUX, Dra. C. Eulalia. Derecho Laboral Cubano Teoría y Legislación, segunda edición, Tomo I, editorial Félix Varela, La Habana, 2007.

42. Instituciones del derecho laboral cubano. La Habana. 2008. Editorial Félix Varela. Cuba.

43. ORGANIZACIÓN MUNDIAL DEL COMERCIO. ONU. 1993. Regulaciones sobre el Derecho Mercantil.

44. ORGANIZACIÓN INTERNACIONAL DEL TRABAJO. ONU. Regulaciones sobre el autoempleo, el trabajo por cuenta ajena.

45. ZAVARO Barbano, León y Martínez García, Ceferino: Auditoría Informática. Consultoría Jurídica Internacional.

\section{Normas jurídicas consultadas}

46. Constitución de la República de Cuba. Reformas aprobadas por la Asamblea Nacional del Poder Popular. Granma, Ciudad de La Habana, edición especial MINJUS, junio 1992. Gaceta Oficial Extraordinaria no. 3, de 31 de enero de 2003.

47. Código de Comercio de 1885 de la República de Cuba.

48. Ley No 7 de 19 de agosto de 1977, Ley de Procedimiento Civil, Administrativo, Laboral y Económico. Modificaciones al amparo del Decreto Ley No. 241. (2006)

49. Ley No. 14 de 1977, Ley cubana de Derecho de Autor

50. Ley No. 49 de 28 de diciembre de 1984, Código de Trabajo. Editora MINJUS. La Habana. Cuba. GOE No. 3 de 24-04-1985.

51. Ley No. 59 de 16 de julio de 1987, Código Civil (1989): Ed. Ciencias Sociales, Ciudad de La Habana. GOE No. 9 de 15-10-1987.

52. Ley No. 62 de 30 de abril de 1988, Código Penal (2004). Editora MINJUS. La Habana. Cuba. GO Esp. No. 3 de 30-12-1987.

53. Ley No. 73 de 4 de agosto de1994, Ley del Sistema Tributario (s. f.): Ed. Sangova, Madrid, col. Textos Legales. GO Ext. No. 8 de 5-08-1994.

54. Ley No. 77 de 5 de septiembre de 1995, Ley de la Inversión Extranjera, Ed. Sangova, Madrid, col. Textos Legales. GOE No. 3 de 6-09-1995. 
55. Ley No. 107, de 1 de agosto de 2009. Ley de la Contraloría General de la República.

56. Ley No. 113, Ley del Sistema Tributario. GOE No. 53, de fecha 21-112012.

57. Decreto Ley No. 67 de 1979. De organización de los Organismos de la Administración Central del Estado. Editora Ministerio de Justicia. La Habana. Cuba. GO Ext. No. 9 de 19-04-1983.

58. Decreto Ley No. 99 de 1987. De las contravenciones personales. Gaceta Oficial Extraordinaria de 25 de diciembre de 1987. La Habana. Cuba. GO Ext. No. 12 de 25-12-1987.

59. Decreto Ley No. 141 de 8 de septiembre de 1993 del Consejo de Estado, Sobre el ejercicio del trabajo por cuenta propia. Editora MINJUS. La Habana. Cuba.

60. Decreto Ley No. 147 de 1995 De reorganización de los Organismos de la Administración Central del Estado. Editora Ministerio de Justicia. La Habana. Cuba. GO Ext. No. no. 2 de 21-04-1994.

61. Decreto Ley No. 174 de 9 de mayo de 1997 del Consejo de Estado, De las contravenciones personales de las regulaciones del trabajo por cuenta propia. Publicado en la Gaceta Oficial de la República, edición ordinaria, de 30 de junio.

62. Decreto Ley No. 199, sobre la seguridad y protección de la información oficial.

63. Decreto No. 100 de 1983. De la Inspección Estatal. Editora Ministerio de Justicia. La Habana. Cuba. GOO no. 14 de 10-02-1982

64. Decreto No. 308 de 2012. Reglamento de las normas tributarias y los procedimientos tributarios. GOE No. 53 de 2012.

65. Resolución No. 1 del Ministerio del Interior. Reglamento sobre la seguridad y protección de la información oficial.

66. Resolución del Ministerio del interior. Reglamento para la Criptografía y el Servicio Cifrado en el territorio Nacional.

67. Resolución No. 6 de 1996. Reglamento sobre seguridad informática. Ministerio del Interior.

68. Resolución No. 60 de 2011. Sobre del sistema de control interno. Contraloría General de la República.

69. Normas de Auditoría. Ministerio de Auditoría y Control. Manual del auditor. República de Cuba.

70. Resolución Conjunta No. 1 de 18 de abril de 1996, "Reglamento del ejercicio del trabajo por cuenta propia" del Ministerio de Trabajo y Seguridad Social y Ministerio de Finanzas y Precios. Editora MINJUS. La Habana. Cuba.

71. Resolución No. 11 de 25 de marzo de 2004 del Ministerio de Trabajo y Seguridad Social, Reglamento sobre el ejercicio del trabajo por cuenta propia. Editora MINJUS. La Habana. Cuba.

72. Resolución No. 9 de 11 de marzo de 2005 del Ministerio de Trabajo y Seguridad Social. Reglamento sobre el ejercicio del trabajo por cuenta propia. Editora MINJUS. La Habana. Cuba.

73. Instrucción No. 27 de 15 de junio de 2006 del Viceministro de Trabajo y Seguridad Social, "Procedimiento para otorgar la Licencia para ejercer el Trabajo por Cuenta Propia". Editora MINJUS. La Habana. Cuba. 
74. Compendio de Regulaciones del Ejercicio del Trabajo por Cuenta Propia y los procesos de reducción de plantillas infladas, Empresa Poligráfica, Holguín, 2011. Editora MINJUS. La Habana. Cuba.

\section{Diccionarios consultados}

75. DICCIONARIO JURÍDICO ENCICLOPÉDICO. Consultor digital de Honduras. 2005.

76. DICCIONARIO DE CIENCIAS JURÍDICAS, POLÍTICAS Y SOCIALES. Guatemala. 1era edición, versión digital.

77. DICCIONARIO DIGITAL LARROUSE. 2010. Versión Windows.

78. DICCIONARIO DE VOCABULARIO JURÍDICO. Autor: Dr. Oriol Mederos. Editorial Oriente. 1998. Cuba.

79. DICCIONARIO CERVANTES. Autor: Alvero Francés, F. Editorial Pueblo y Educación. La Habana. Cuba. 1980.

80. DICCIONARIO DE SINÓNIMOS Y ANTÓNIMOS. Autor: Sainz de Robles, F. C La Habana. Editorial Científico Técnica. Cuba. 1978.

81. DICCIONARIO DE CIENCIAS JURÍDICAS, POLÍTICAS Y SOCIALES. Argentina, Editora HELIASTA. 1982.

82. DICCIONARIO DE DERECHO. Editorial Porrúa. México. 1997.

83. DICCIONARIO JURÍDICO ESPASA. Editorial Espasa. CALPE. Madrid. 1994.

84. DICCIONARIO JURÍDICO MEXICANO. 14ª . Ediciones Porrúa UNAM. México. 2000.

85. ENCICLOPEDIA JURÍDICA OMEBA. Argentina. 1976.

86. DICCIONARIO DE TERMINOS INFORMATICOS. 2003. Editora Ciencias. Cuba.

\section{Páginas web consultadas}

87. http://vlex.it/vid/informatica-juridica-derecho-informatico-

37801867\#ixzz1JqNFh6qT. Consultado el 10 de diciembre de 2012.

88. http://law.com/newswire/lus cibernetica. Consultado 10 de diciembre 2012.

89. http://www.alfa-redi.org/rdi-articulo.shtml?x=292. Consultado 10 de diciembre 2012.

90. http://www.ecured.cu/Trabajador_por_cuenta_propia/ 24 de octubre de 2012.

91. http://www.cubadebate.cu/ trabajo-por-cuenta-propia-emplea-ya-a-330-000cubanos/ 24 de octubre de 2012.

92. http://www.cubasi.cu/index.php?...trabajo-por-cuenta-propia/ 24 de octubre de 2012.

93. http://www.slideshare.net/rosafol/el-trabajo-por-cuenta-propia/ 24 de octubre de 2012.

94. http://es.wikipedia.org/wiki/Derecho_laboral/ 24 de octubre de 2012.

95. http://www.e-conomic.es/programa/glosario/trabajador-cuenta-ajena/ 24 de octubre de 2012. 